\section{Automated squeeze test (Gaenslen's manoeuvre) to identify patients with arthralgia suspicious for progression to RA: improving time delay to rheumatology consultation}

We read with interest the article by van Steenbergen $e t a l^{1}$ and the response by Mankia et $a l^{2}$ In the former, a definition of suspicious arthralgia was proposed and in the latter a new approach to identifying individuals at risk of progression to rheumatoid arthritis (RA) was discussed. We agree with Mankia et al that general practitioners (GPs) are the first contact for those patients at risk. In other countries a delay in referring patients with RA has been seen, and we have similarly detected a delay of 28.2 (SD 46.9) months. $^{3}$ Thus, we are interested in clinical signs that allow GPs to identify patients with arthralgia suspicious for progression to RA-particularly, use of the squeeze test (ST) (also known as Gaenslen's compression test). ${ }^{4}$ Previously, we found that the ST was useful in identifying RA progression in patients with undifferentiated arthritis in a year of follow-up. ${ }^{5}$

Because of the importance of physical examination and also medical education, we devised a study protocol. In the first phase, we noted the variations in the ST results by certified rheumatologists, and found important differences. ${ }^{6}$ This supports the observations of van Steenbergen $\mathrm{et}^{\mathrm{al}} \mathrm{l}^{7}$ about the importance of clinical expertise and its reliability for diagnosing patients with arthritis. In the second phase, having found differences in performance of the test, we constructed an automated device to evaluate the ST performance. We carried out a study in patients with established RA and in healthy individuals. The median squeeze force necessary to evoke pain in the RA group was 3.07 (IQR 2.4) kg and 2.78 (IQR 3.8) $\mathrm{kg}$ in the right and left hand, respectively; and in the healthy group these values were 4.2 (IQR 9.5) $\mathrm{kg}$ and 4.6 (9.7) $\mathrm{kg} .{ }^{8}$

Mankia et al, in their study, ${ }^{2}$ sought to reduce the impact of clinical inexperience by using the anti-cyclic citrullinated peptide test for the detection of individuals at risk of RA. However, the cost-benefit of this test is controversial and several causes contribute to the dearth of such specialised studies-for example, inadequate clinical expertise of the first contact physician, inadequate number of rheumatologists in a given population, long waiting times for evaluation or even economic factors. The automated test could reduce this gap. The force of the ST which is applied to distinguish between a healthy individual, and a patient with active disease is already established. The strength of the squeeze needed to screen the patient with arthralgia which it is suspected will progress to RA is in the process of determination. The objective of all investigations is to develop an easy to use, cheap tool that can identify $\mathrm{RA}$ in patients at an early stage.
David Vega-Morales, Jorge A Esquivel-Valerio, Ana C Arana-Guajardo

Servicio de Reumatologia, Departamento de Medicina Interna, Hospital Universitario Dr Jose Eleuterio Gonzalez. Universidad Autonoma de Nuevo Leon, Monterrey, Mexico

Correspondence to Dr David Vega-Morales, Servicio de Reumatologia, Departamento de Medicina Interna, Hospital Universitario Dr Jose Eleuterio Gonzalez, Universidad Autonoma de Nuevo Leon, Monterrey, Nuevo León 64040 , Mexico; drdavidvega@yahoo.com.mx

Acknowledgement Colegio Mexicano de Reumatologia A.C.

Competing interests None declared.

Provenance and peer review Not commissioned; internally peer reviewed.

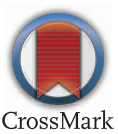

To cite Vega-Morales D, Esquivel-Valerio JA, Arana-Guajardo AC. Ann Rheum Dis 2017;76:e40.

Received 26 January 2017

Accepted 30 January 2017

Published Online First February 272017

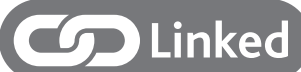

http://dx.doi.org/10.1136/annrheumdis-2017-211230

http://dx.doi.org/10.1136/annrheumdis-2017-211231

Ann Rheum Dis 2017;76:e40. doi:10.1136/annrheumdis-2016-211205

\section{REFERENCES}

1 van Steenbergen HW, Aletaha D, Beaart-van de Voorde LJ, et al. EULAR definition of arthralgia suspicious for progression to rheumatoid arthritis. Ann Rheum Dis 2017;76:491-6.

2 Mankia K, Nam J, Emery P. Identifying arthralgia suspicious for progression to rheumatoid arthritis. Ann Rheum Dis 2017:76:e14.

3 Vega-Morales D, Covarrubias-Castañeda Y, Arana-Guajardo AC, et al. Time delay to rheumatology consultation: rheumatoid arthritis diagnostic concordance between primary care physician and rheumatologist. Am J Med Qual 2016;31:603.

4 Wiesinger T, Smolen JS, Aletaha D, et al. Compression test (Gaenslen's squeeze test) positivity, joint tenderness, and disease activity in patients with rheumatoid arthritis. Arthritis Care Res (Hoboken) 2013;65:653-7.

5 Arana-Guajardo A, Pérez-Barbosa L, Vega-Morales D, et al. Application of a prediction model for the progression of rheumatoid arthritis in patients with undifferentiated arthritis. Reumatol Clin 2014;10:360-3.

6 Vega-Morales D, Esquivel-Valerio JA, Garza-Elizondo MA. Do rheumatologists know how to squeeze? Evaluations of Gaenslens maneuver. Rheumatol Int 2015:35:2037-40.

7 van Steenbergen HW, van der Helm-van Mil AH. Clinical expertise and its accuracy in differentiating arthralgia patients at risk for rheumatoid arthritis from other patients presenting with joint symptoms. Rheumatology (Oxford) 2016;55:1140-1.

8 Vega-Morales D, Garza-Elizondo MA, Esquivel-Valerio JA, et al. Evaluacion de la maniobra de compresion de Gaenslen automatizada en pacientes con AR: estudio exploratorio (Spanish). Reumatol Clin 2016;12:10. 